\title{
Asthma Disease Management: A Worksite-Based Asthma Education Program
}

\author{
WAYNE N. BURTON, M.D., ${ }^{1,2}$ ALYSSA B. SCHULTZ, M.S., ${ }^{3}$ \\ CATHERINE M. CONNERTY, R.N., ${ }^{1}$ CHIN-YU CHEN, PH.D., ${ }^{3}$ \\ and DEE W. EDINGTON, PH.D. ${ }^{3}$
}

\begin{abstract}
Asthma accounts for an estimated 3 million workdays lost each year in the United States in addition to reduced worker productivity. Although asthma disease management programs are relatively common in managed care organizations, they have generally not been offered at the workplace. Seventy-six employees participated in a five-session worksite-based asthma education program. A total of 47 of 76 (61.8\%) employees completed baseline and 12-month follow-up Asthma Therapy Assessment Questionnaires (ATAQ). The ATAQ includes measurement of poor asthma control, behavior/attitude barriers, knowledge barriers, patient/ provider communication barriers, and efficiency. Significant improvement was noted in measures of asthma control $(p<0.05)$, communication $(p<0.005)$, knowledge $(p<0.001)$, and the total ATAQ Index declined from 5.53 to $4.04(p<0.001)$. Employee satisfaction results for the program were exceptionally high. A worksite-based asthma education program should reduce medical care costs, worker absenteeism, and improve worker productivity. The worksite can be a very effective location for disease education programs.
\end{abstract}

\section{INTRODUCTION}

A STHMA AFFECTS more than 10 million American adults and is one of the leading causes of lost productivity at school and at work. ${ }^{1}$ It accounts for an estimated 3 million workdays lost annually in the United States, and over \$1 billion is spent each year on healthcare for asthma alone.

In 1997, more than 30.5 million prescriptions for asthma medications were filled. In addition, there were approximately 1.2 million emergency room visits and 445,000 hospital inpatient days attributable to acute asthmatic attacks. $^{2}$ In 1994, 14.6 million individuals (56.1 per 1,000) reported having attacks of asthma during the preceding 12 months, a self-reported prevalence that was $75 \%$ greater than the comparable figure for $1980 .^{3}$ Despite the increasing availability of effective treatments for asthmatic attacks, the numbers of asthma-related hospitalizations and deaths have been rising. 4

According to Musich et al., the total cost of asthma in 1997 dollars was $\$ 15.1$ billion, including $\$ 11.8$ billion in direct costs and $\$ 3.3$ billion to indirect costs. ${ }^{5}$ The National Heart, Lung, and Blood Institute found that inpatient hospitalizations accounted for $45 \%$ of the direct expenditures, and the cost of drugs accounted

\footnotetext{
${ }^{1}$ Bank One, Chicago, Illinois.

${ }^{2}$ Northwestern University Medical School, Chicago, Illinois.

${ }^{3}$ University of Michigan, Health Management Research Center, Ann Arbor, Michigan.
} 
for approximately $30 \%$ of the total cost. ${ }^{6}$ The average annual cost for treating a single asthmatic patient in 1995 was estimated to range from $\$ 2,584$ to $\$ 5,710$. $^{7}$

Asthma is a controllable disease; however, control cannot be accomplished without patient education and involvement in a planned disease management strategy. An example of this strategy is the asthma guidelines developed by a panel of experts convened by the National Heart, Lung, and Blood Institute. ${ }^{8}$

Many studies demonstrate the value of patient education and disease management in asthmatics. Evidenced-based disease management interventions have reduced healthcare costs in patients with asthma. Gaioni et al. studied a cohort of 207 patients 1 year after they had completed a disease management program at an asthma center. ${ }^{9}$ The patients showed a $78 \%$ reduction in hospitalization, a $73 \%$ reduction in emergency department visits, and a $48 \%$ reduction in unscheduled physician visits. Overall net savings were estimated to average $\$ 2,714$ per patient per year. Patients' knowledge of self-care test scores for asthma increased from $48 \%$ to $96 \%{ }^{9}$

There have been numerous reports documenting the beneficial effects of increasing a patients' knowledge of asthma self-management. Kotses et al., demonstrated that soon after a 7-week asthma education program, patients showed improvement in asthma management skills and cognitive abilities, had fewer asthma symptoms, and experienced a reduction in physician visits. ${ }^{10}$ At the end of 1 year, in comparison with a control group receiving routine care, program participants had fewer asthmatic attacks, reduced use of medications, showed improvement in cognitive measures, and increased reliance on self-management skills. ${ }^{10}$ Zimmer et al. evaluated the results of a year-long, in-home, telephonic education and training program in a group of 40 adults considered to have moderate, severe, or uncontrolled asthma. The participants reported a decrease in absenteeism and fewer days of reduced productivity. ${ }^{11}$

Similarly, Snyder et al. randomly assigned 79 adult asthmatics to a waiting list or to a program of training in self-management and found that as knowledge about asthma control in- creased in the study group compared to the controls, the number of asthmatic attacks decreased. $^{12}$

Finally, Soucy and Siderov studied 312 asthmatics among the members of a group-model health maintenance organization who enrolled in an asthma disease management program. One year later, the average cost of claims for asthma treatment had decreased from \$28 per member per month to $\$ 20$ per member per month. ${ }^{13}$

Despite such well-documented demonstrations of the value of health education programs in the management of asthma, many patients are not receiving them. Reasons for the lack of availability of asthma disease management programs include nonreimbursable services, insufficient numbers of asthmatics in a medical practice, and lack of a trained nursing or health educator to conduct the program.

Patients must also accept responsibility for the management of a chronic disease such as asthma. They need to appreciate the potential value of disease management and devote time to educational programs. Although asthma education and disease management programs may be offered in the healthcare setting, they may be offered during working hours when employed asthmatics, already plagued by absences caused by acute attacks, may be reluctant to take more time from work.

The objective of this study was to evaluate a worksite-based education program targeted at employees with nonoccupational asthma. This was a relatively low-cost program to improve control of asthma in workers.

\section{METHOD}

Bank One, created in October 1988 by the merger of the First Chicago NBD Corporation (FCNBD) and Banc One, is the fourth largest U.S. bank holding corporation. It has over 80,000 employees. In September 1998, 1 month before the merger, the FCNBD Medical Department offered a worksite-based program called the "FirstAir Asthma Education Program" to the 12,000 employees at its downtown Chicago location. The objectives of this program were previously described: they included 
education of asthmatic employees on the value and importance of optimal management and to train them in the elements of self-care. ${ }^{14}$ The incentive to the employer was the prospect of increased productivity reflecting a potential diminution in absences and impaired work performance, enhanced employee morale, and a decrease in medical claims.

\section{The FirstAir Asthma Education Program}

The program consisted of five weekly 1-hour sessions during the lunch hour. The sessions were conducted by a well-trained clinical asthma nurse specialist and covered such topics as symptoms of asthma, recognition of triggers and warning signs of asthmatic attacks, medications and other treatments for asthma, use and care of peak flow meters, nebulizers and metered-dose inhalers, handling emergencies, and how to keep an asthma diary (see Table 1).

Incentives were offered to encourage completion of the program. They included a free healthy lunch at every session; a free 1-year subscription to Asthma Magazine (\$22 retail); a wellness tote bag filled with educational materials such as keeping an asthma-friendly home environment; a copy of How to Outsmart Your Allergies; a popular book by Art Ulene, M.D., the well-known television commentator on health topics; and a drawing for a number of items useful for asthmatics such as a cold weather mask, a pillow protector, and an inhaler cover. In addition, those who completed a health questionnaire focused on asthma were given a \$25 gift certificate. Prior to entering the program, each participant completed a computerized health risk appraisal that, in addition

\begin{tabular}{|lc|}
\hline & \multicolumn{2}{c|}{ Table 1. } & Curriculum of the \\
Asthma & Education Program \\
\hline Session number & \multicolumn{1}{c}{ Topics covered } \\
\hline One & Understanding asthma \\
Two & Getting the most from your \\
& medications \\
Three & Asthma triggers \\
Four & Asthma monitoring \\
Five & Putting it all together: questions \\
& and answers \\
\hline
\end{tabular}

to behavioral and other health information, included measurements of blood pressure, serum cholesterol, and height and weight to calculate body mass index.

Employees with asthma were identified by using Bank One's integrated health data warehouse, nicknamed OMNI (Occupational Medical and Nursing Information). ${ }^{15}$ The confidential database, access to which is limited to the Medical Department staff, includes health insurance claims (inpatient, outpatient, and pharmacy), short-term disability absences, and a computer-based medical record. Claims bearing ICD-9 (International Classification of Diseases) diagnostic codes relating to asthma were used. An occupational health nurse, trained in the program's objectives and content, interviewed each of these individuals and invited them to participate. In addition, information regarding the program along with an invitation to participate was sent to each of the 12,000 Bank One employees working in downtown Chicago. In all, 76 participants signed up for the program.

The instrument used to evaluate the effectiveness of the FirstAir program was the Asthma Therapy Assessment Questionnaire (ATAQ) developed and distributed by Merck \& Company, Inc. [West Point, PA, (Fig. 1)]. The ATAQ measures an individual's self-reported severity of asthma symptoms, medication compliance barriers, deficiency in knowledge of asthma, and barriers to effective communication with his or her healthcare provider. ${ }^{16,17}$ Participants were asked to complete the ATAQ at baseline, at the end of the 2-month program, and 4 and 12 months following completion of the program. At the same time, participants were asked to report any absences from work during the prior period.

Responses to the ATAQ surveys were summed to produce scores on the following asthma disease management issues: asthma control, behavior/attitude barriers, knowledge barriers, communication barriers, and self-efficacy issues. The University of Michigan Health Management Research Center independently scored and analyzed the responses. Each participant received a personal letter describing his or her individual specific risk indicators and suggesting particular recommendations for im- 


\section{Yes No}

1) Has any doctor or medical provider ever told you that you have chronic bronchitis, emphysema, COPD (Chronic Obstructive Pulmonary Disease)?

2) Has any doctor or medical provider ever told you that you have asthma?

(If no, please stop here and return the questionnaire)

3) In the past $\mathbf{4}$ weeks, did you feel that your asthma was well controlled?

Yes No Unsure

4) In the past 12 months, did you miss any work, school or normal daily activity

because of your asthma?

5) In the past 12 months, did your asthma wake you up at night?

6) In the past 4 weeks, did you miss any work, school or normal daily activity because of your asthma?

7) In the past 4 weeks, did your asthma wake you up at night?

8) In the past 12 months, have you at any time taken medicine(s) for your asthma?

(If no, please stop here and return the questionnaire)

9) Are you dissatisfied with any part of your current asthma treatment?

Yes No Unsure

10) Do you believe you are able to take your asthma medicine(s) as directed?

11) Do you believe your medicine(s) is useful in controlling your asthma?

12) In the past 12 months, has your doctor or medical provider gone over with you how to take your asthma medicine(s)?

13) Do you and your doctor or medical provider make decisions together about your asthma treatment?

14) Does your doctor or medical provider know how you prefer to take your asthma medicine(s) [such as by pill or inhaler once a day or more than once a day]?

15) Do you have a written treatment plan from your doctor or medical provider on what to do if you are having an asthma attack?

16) Do you have a written plan from your doctor or medical provider on how to take your asthma medicine(s) on days when you are NOT having an asthma attack?

17) Do you use an inhaler for quick relief from asthma symptoms?

If you answered Yes to \#17:

In the past 12 months, on days you use an inhaler for quick relief, how many puffs a day do you usually take?

$\square$ to 4 puffs $\square 5$ to 8 puffs $\square 9$ to 12 puffs $\square$ more than 12 puffs

In the past 4 weeks, what was the highest number of puffs a day you took of this inhaler? 
18) Has your doctor or medical provider ever prescribed an asthma inhaler or pill

that is NOT used for quick relief, but is used to control your asthma?

If you answered Yes to \#18: What best describes how you take this medicine?

(check one) $\square$ I take it every day.

$\square$ Some days I take it, but other days I don't.

$\square$ I used to take it, but now I don't.

$\square$ I only take it when I have symptoms.

$\square$ I never took it.

19) What is your sex? Male $\square$ Female

20) How old are you? $\square$ Under $18 \quad \square$ 18-25 $\square$ 26-45 $\square$ 46-55 $\square$ 56-65 $\square$ over 65

21) Thank you for completing this questionnaire! Is there anything you would like to tell us about your asthma or the care you are receiving?

\begin{tabular}{|c|c|}
\hline \multicolumn{2}{|l|}{ ATAQ SCORING SYSTEM } \\
\hline Poor Asthma Control & Question \# \\
\hline -- Work/school or normal activity loss & 4,6 \\
\hline -- Nocturnal asthma & 5,7 \\
\hline -- Overuse/increased us of beta-agonist & 17 \\
\hline -- Self assessed & 3 \\
\hline Behavior/Attitude Barriers & Question \# \\
\hline -- Satisfaction with regimen & 9 \\
\hline -- Use of Controller meds. & 18 \\
\hline Knowledge Barriers & Question \# \\
\hline $\begin{array}{l}-- \text { Confusion between controller } \& \text { reliever } \\
\text { medicines }\end{array}$ & 17,18 \\
\hline Patient/Provider Communication Barriers & Question \# \\
\hline -- Written treatment plan & 15,16 \\
\hline -- Preferences about regimen and form of medicine & 14 \\
\hline -- Joint decision making & 13 \\
\hline -- Review of asthma medications & 12 \\
\hline Efficacy & Question \# \\
\hline -- Belief in ability to take medicines correctly & 10 \\
\hline -- Belief in efficacy of medicines & 11 \\
\hline
\end{tabular}

FIG. 1. Asthma Therapy Assessment Questionnaire (ATAQ). Reprinted with permission from Merck \& Company, Inc. 
proving asthma self-management skills. Participants were urged to discuss the content of this letter with their personal physicians.

Poor asthma control is defined by the ATAQ as the presence of nocturnal awakenings due to respiratory difficulties, days of absence or inability to perform usual activities, increased use of beta-agonists, and exercise-induced symptoms since the last ATAQ survey.

Behavior/attitude barriers evaluated the employee's satisfaction with the treatment plan, the medications prescribed, and the healthcare in general. Questions also addressed potential compliance with the regimen of medications prescribed such as failure to use controller/ prevention medications or overuse of reliever/ rescue medications.

The measure of self-efficacy on the ATAQ probed the individual's personal beliefs and attitudes relating to asthma, the medications prescribed, and the resources available to manage the disease.

ATAQ questions relating to patient/ provider communication barriers explore the patients' desire, willingness, and ability to communicate with their healthcare provider about asthma symptoms and responses to treatment during routine follow-up or other office visits. They also assess whether or not the patient has the resources needed to assist in self-management of the disease such as a special asthma action plan.

ATAQ questions on knowledge barriers test patients' understanding of the proper use of their medications, what they are intended to do, and when and how often they should be used, including the continued use of controller medications to prevent recurrent attacks.

\section{Employee demographics}

The program began with 76 participants. Their mean age was 39.3 years (range, 23 to 69 years), with $83.1 \%$ females and $16.9 \%$ males. Ethnicity was 50.6\% Caucasian, 29.8\% African American, 10.4\% Asian, 7.8\% Hispanic, and $1.3 \%$ unknown. Demographics of participants in the asthma education program did not differ significantly from the overall bank population demographics.

\section{Results of the ATAQ survey}

Of the 76 employees who began in the program, 68 returned completed ATAQ questionnaires after 2 months, 53 completed the 4month follow-up, and 47 completed the final questionnaire at 12 months. Forty-one participants $(53.9 \%)$ completed all four ATAQ questionnaires. They did not differ significantly in the demographic variables (age, gender, and ethnicity) from the original cohort of 76. Figure 2 shows the ATAQ scores for 47 participants who completed both a baseline and 12-month follow-up questionnaire.

There was a statistically significant $(p<0.05)$ improvement in ATAQ scores for control, communication, knowledge, and the total ATAQ index. No statistically significant change was found for behavior and self-efficacy ATAQ scores.

\section{Control barriers}

The control barrier score is the sum of responses to four questions regarding (1) poor asthma control, (2) absences from school or work or uncompleted activities, (3) nocturnal awakening because of asthma, and (4) overuse or increased use of reliever medications. The score may range from 0 to 4 . The mean score for control barriers showed a positive trend, declining from 1.83 at baseline to 1.28 at 12 months (see Fig. 2).

The number of employees who reported no control barriers increased from $11 \%$ at baseline to $28 \%$ after 4 months $(p<0.01)$. The number of employees who reported all four control barriers decreased from $7 \%$ at baseline to $0 \%$ at 4 months $(p<0.01)$. These scores were maintained at the 12-month follow-up.

Medication usage is an important factor in asthma control. Figure 3 shows the distribution of medication usage at baseline and 12-month follow-up. Statistically significant $(p<0.05)$ improvement was noted in the number of participants reporting use of an asthma controller medication on a daily basis.

\section{Communication barriers}

The communication barriers score is derived from the responses to five questions regarding 


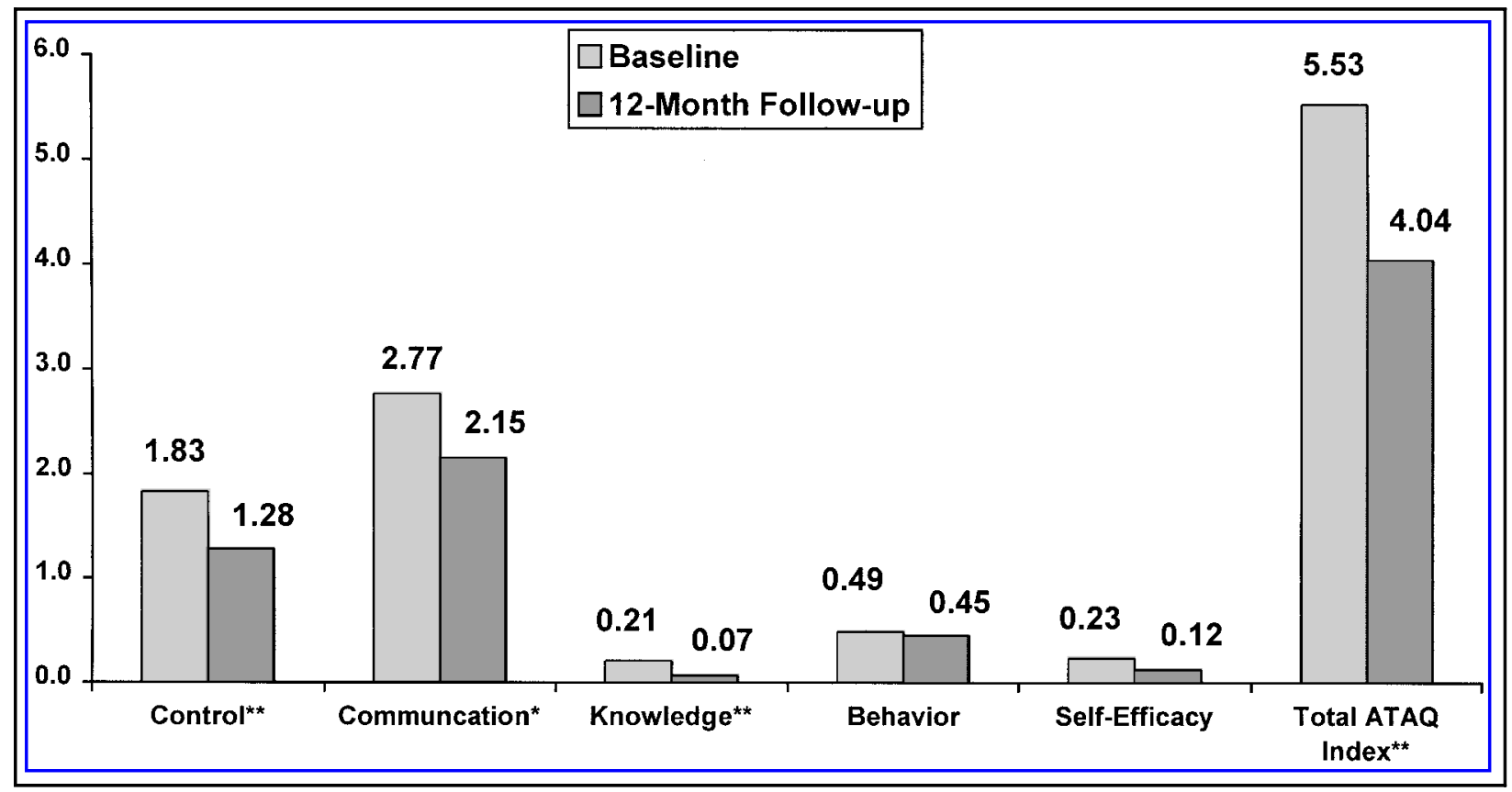

FIG. 2. Asthma Therapy Assessment Questionnaire (ATAQ) scores at baseline and 12-month follow-up ( $n=47)$. ${ }^{*} p<0.05 .{ }^{* *} p<0.001$.

(1) patient and provider review of medications, (2) patient and provider share in making of therapy decisions, (3) written action/treatment plans for exacerbations, (4) routine management recommendations developed jointly by patient and provider, and (5) provider being aware of patient's preferences for therapy. The score may range from 0 to 5 . The number of participants with a written treatment control plan increased significantly from baseline to the 12-month follow-up. The Merck communication score decreased from 2.77 at baseline to 2.15 at 12 months $(p<0.05)$. Reviewing med- ications with the physician, making decisions jointly with the physician, and having treatment preferences known to the physician remained consistently high throughout the study period. Having a written treatment plan for acute asthma attacks (in contrast to asthma control) increased from $10 \%$ to $17 \%$ of participants $(p$, not significant).

\section{Knowledge barriers}

The knowledge barriers were evaluated by the yes/no responses to: (1) patient doesn't

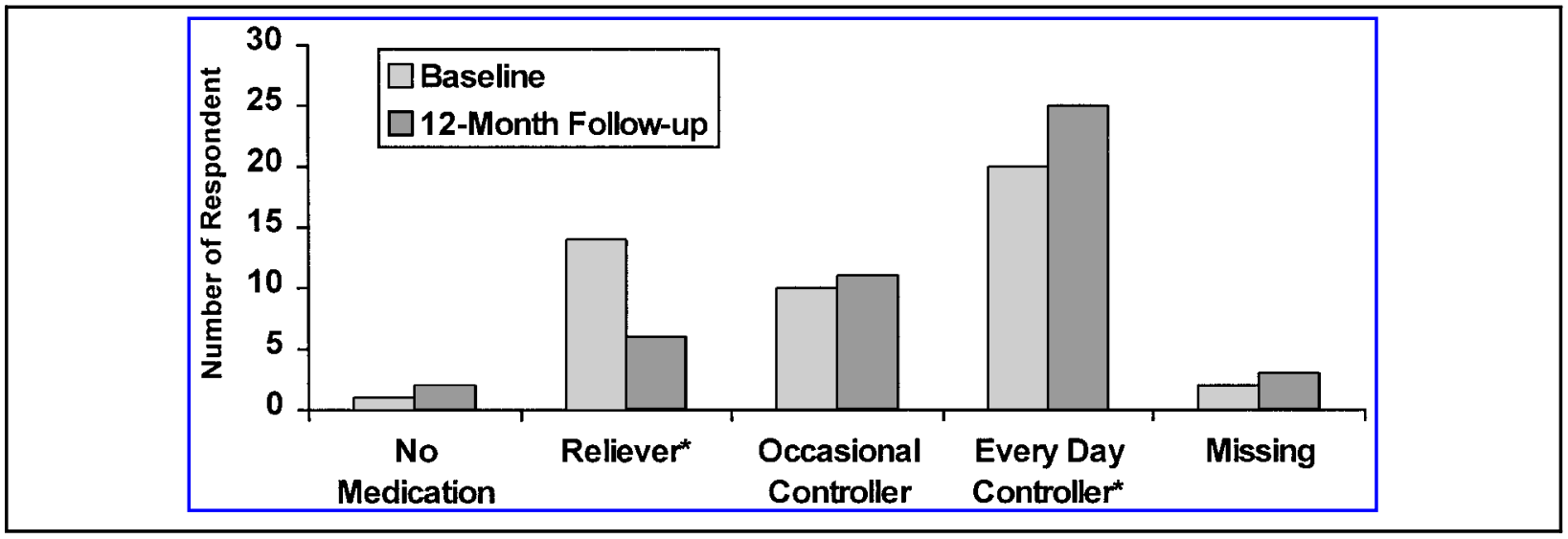

FIG. 3. Asthma medication usage before and after completion of the FirstAir Asthma Education Program $(n=47)$. $p<0.05$. 
know if a tablet and/or inhalant has been prescribed for the relief of symptoms, (2) patient doesn't know if a pill and/or inhalant has been prescribed for asthma control, and (3) patient reports that the asthma was well controlled during the past month yet overused reliever medication. Very few employees reported having more than one knowledge deficit. The mean knowledge barrier score declined from 0.21 at baseline to 0.07 at 12 months $(p<0.001)$.

\section{Behavior barriers}

There were two attitude/behavior barriers: (1) Is the patient dissatisfied with his/her current asthma treatment? And (2) A controller medication has been prescribed but the patient is not using it every day. The average behavior barrier score declined from 0.49 at baseline to 0.45 at the 12 -month follow-up.

The number of employees reporting dissatisfaction with their current asthma treatment remained low from baseline through the follow-up. Significant changes were seen, however, in the use of controller medications. The number of participants who reported having a prescription for controller medication increased from $59 \%$ at baseline to $76 \%$ at the 12 month follow-up $(p<0.05)$.

\section{Self-efficacy barriers}

The self-efficacy barriers included: whether the respondents believe that they were able to take their medications as directed and (2) whether they believe that their medications are useful in the treatment of their attacks (see Fig. 2). Self-efficacy barriers were low at baseline $(98 \%$ reported being able to take their medications as directed, and $80 \%$ believed their medications to be useful). This is not surprising when one considers the education levels of these employee participants. Nevertheless, the mean self-efficacy scores declined from 0.23 at baseline to 0.12 at the 12 -month follow-up, indicating that improvement was still possible.

\section{Overall ATAQ Index of disease management}

The total barrier index is the sum of the five ATAQ disease management barrier scores. The number of participants reporting no barriers in each of these domains increased at the 4-month follow-up. The average total barrier index reported at baseline was 5.53; it decreased to 4.04 at the end of 1 year $(p<0.05)$ (see Fig. 2). This consistent trend toward improvement demonstrates that the participants retained the positive effects of the educational program for at least a year and probably longer.

\section{Program satisfaction}

Sixty-two participants $(79.8 \%)$ completed a program evaluation survey at the conclusion of the FirstAir Asthma Education Program. Results (see Table 2) show that $95 \%$ of participants rated the program as excellent or very good. Almost $80 \%$ rated the instructor as excellent or very good, and $84 \%$ gave high marks for the written materials. Seventy-three percent of participants noted they would take steps to reduce known asthma triggers, a large part of controlling asthma and preventing attacks, as a result of the educational program. Of those who reported seeing a doctor since the program, 33\% claimed the program significantly promoted communication with their physician.

\section{DISCUSSION}

Asthma affects approximately $6.8 \%$ of the Bank One employee population. This is similar to the prevalence reported in the adult U.S. population. In addition to direct healthcare costs, employees may have significant lost onthe-job productivity and absences from work if asthma is not controlled. A population approach to the management of common chronic diseases in the workplace has already been demonstrated to be effective in managed care organizations. Buchner et al. studied 2,734 adult asthmatics in a 500,000-member managed care organization. ${ }^{18}$ The asthma health management program provided education on the National Heart, Lung, and Blood Institute guidelines for the treatment of asthma to physicians as well as providing educational "kits" for patients with asthma. Asthmatic patients reported significant improvement in receiving instructions for a flare-up of their asthma. The 


\begin{tabular}{|c|c|c|}
\hline & $\mathrm{n}$ & Percentage \\
\hline \multicolumn{3}{|l|}{ Rating of the FirstAir program } \\
\hline Excellent & 47 & 76 \\
\hline Very good & 12 & 19 \\
\hline Average & 3 & 5 \\
\hline Fair & 0 & 0 \\
\hline Poor & 0 & 0 \\
\hline \multicolumn{3}{|l|}{ Rating of the instructor } \\
\hline Excellent & 46 & 74 \\
\hline Very good & 13 & 21 \\
\hline Average & 0 & 0 \\
\hline Fair & 0 & 0 \\
\hline Poor & 0 & 0 \\
\hline Missing & 3 & 5 \\
\hline \multicolumn{3}{|l|}{ Rating of the written materials } \\
\hline Excellent & 39 & 64 \\
\hline Very good & 13 & 21 \\
\hline Average & 7 & 11 \\
\hline Fair & 1 & 2 \\
\hline Poor & 1 & 2 \\
\hline \multicolumn{3}{|l|}{ As a result of the FirstAir Program, participants will: } \\
\hline Visit doctor more regularly & 20 & 32 \\
\hline Take medication properly and consistently & 37 & 60 \\
\hline Take steps to reduce known triggers & 45 & 73 \\
\hline Develop written treatment plan with doctor & 26 & 42 \\
\hline \multicolumn{3}{|l|}{ Program promoted communication with doctor ${ }^{\mathrm{a}}$} \\
\hline Significantly & 18 & 33 \\
\hline Some & 20 & 37 \\
\hline Little/no change & 16 & 30 \\
\hline
\end{tabular}

proportion of asthmatics in the populations with one or more inpatient hospitalizations declined from $5.6 \%$ to $4.6 \%(p<0.01)$.

This study demonstrates that significant improvement in asthma control as measured by the ATAQ questionnaire is possible with a worksite-based asthma disease education program. Significant improvement was noted in the measures of asthma control, communication, knowledge, and a total index of asthma management. Employees with asthma had statistically significant improvement in ATAQ scores at 2 months from the beginning of the program and retained the positive effects of the educational intervention for at least 1 year after the program.

An important measure of asthma disease management is the use of controller medica- tions to prevent an acute asthma attack in place of a reliever medication used to respond to an acute attack of asthma. This was associated with a reduction in nighttime awakenings and missed work.

Workplace-based disease management programs for employees are intended to supplement and enhance the education provided by the employee's healthcare provider. Improved asthma control has potential benefits for the employee, employer, and healthcare provider. Reduced medical costs will benefit the employer and health plan. The employee benefits from improved quality of life, reduced out-ofpocket medical costs, and any lost wages from absenteeism. The employer benefits from reduced medical and disability costs and improved worker productivity. 


\section{CONCLUSION}

It has been demonstrated that disease management strategies that focus on both control and prevention of acute asthmatic attacks result in fewer attacks, improved well-being, enhanced work performance, greater productivity, and reduced healthcare costs. In fact, asthma and diabetes have been declared to be prime examples of diseases in which the key elements of disease management may be studied and tested. ${ }^{19,20}$ These elements include patient understanding of the disease and its treatment, enhanced communication between the patient and his/her healthcare provider, and optimal utilization of self-care. They are approached through a properly designed and effectively delivered asthma education program. Unfortunately, even where effective asthma education programs exist in the community, asthmatics do not have access to, or fail to take advantage of, them.

The FirstAir Asthma Education Program described in this article demonstrates how this deficiency may be met through a relatively simple, low-cost, voluntary program provided in the worksite to employees with asthma. This program properly leaves command of disease management in the hands of the employees' personal physicians. It focuses on education of the employee in knowledge of the disease and its treatment, training in self-care, and how to hold up his/her end in the obligatory collaboration with the healthcare provider.

This study also demonstrates the utility of ATAQ as an instrument for evaluating the barriers to effective asthma management and how these barriers are diminished or removed by the asthma education program. ATAQ may also be used in more extended follow-ups to test the persistence of the successes of the program as well as the need to repeat the program due to new asthmatic employees arriving as a result of turnover in or expansion of the workforce.

Finally, although not directly measured, it may be inferred from the data presented herein that the modest cost of the program to the employer was more than matched by the monetary value of the gains in employee well being and productivity.

\section{ACKNOWLEDGMENTS}

The authors acknowledge the work of Colleen Andreoni, R.N., M.S., Clinical Nurse Specialist in asthma, who assisted in the development of the worksite asthma education program. Leon Warshaw, M.D., was very much appreciated for his editing of the original manuscript. Regretably, Dr. Warshaw died shortly before the publication of this paper.

This study was supported in part by an unrestricted educational grant from Merck \& Company, Inc.

\section{REFERENCES}

1. Weiss KB, Gergen PJ, Hodgson TA. An economic evaluation of asthma in the United States. N Engl J Med 1992;326:862.

2. Adams PF, Marano MA. Current estimates from the National Health Interview, 1944: National Center for Health Statistics. Vital Health Stat 1995;10(193):153.

3. Centers for Disease Control and Prevention. Forecasted state-specific estimates of self-reported asthma prevalence-United States, 1998. MMWR Morb Mortal Wkly Rep 1998;47(47):1022

4. Stoloff S. Current asthma management: The performance gap and economic consequences. Am J Manag Care 2000;6(suppl):S918.

5. Musich SA, Burton WN, Edington DW. Costs and benefits of prevention and disease management. Disease Management Health Outcomes 1999;5(3):153.

6. Smith DH, Malone DC, Lawson KA, et al. A national estimate of the economic costs of asthma. Am J Respir Crit Care Med 1997;156(3, pt 1):787.

7. Mushinski M. Average hospital charges for asthma treatment: United States, 1995. Stat Bull Metrop Insur Co 1997;78(2):26.

8. National Asthma Education and Prevention Program: Guidelines for the Diagnosis and Management of Asthma. Expert Panel Report 2. Bethesda, MD: National Institutes of Health; 1997. NIH Publication No. 94-405, 1997.

9. Gaioni SJ, Korenblat-Hanin M, Fisher EB, Korenblat P. Treatment outcomes in an outpatient asthma center: Retrospective questionnaire data. Am J Manag Care 1996;2(8):999.

10. Kotses H, Bernstein IL, Bernstein DI, et al. A self-management program for adult asthma. J Allergy Clin Immunol 1995;95:529.

11. Zimmer LO, Almond MJ, Jones D, et al. One-year outcomes from a computer-based disease management program: The Individualized Asthma Care Training Program $\left(\mathrm{FACT}^{\circledR}\right)$. Disease Manage 2000;3:65.

12. Snyder SE, Winder JA, Creer T. Development and evaluation of an adult asthma self-management program: Wheezers anonymous. I Asthma 1987;24:153. 
13. Soucy B, Siderov J. Asthma and disease management: History and development within an integrated healthcare system. Disease Manage 1998;1:259.

14. Burton WN, Connerty CM, Schultz AB, Chen CY, Edington DW. Bank One's worksite-based asthma disease management program. J Occup Environ Med 2001; In Press.

15. Burton WN, Hoy DA. First Chicago's integrated health data computer system. Managed Care Q 1993; $1: 18$.

16. Vollmer WM, Markson L, O'Connor E, et al. Association of asthma control with health care utilization and quality-of-life. Am J Respir Crit Care Med 1999; 160:1647.

17. Markson LE, Vollmer WM, Fitterman L, et al. Insight to patient dissatisfaction with asthma treatment. Arch Intern Med 2001;16:379.

18. Buchner DA, Butt LT, De Stefano A, Edgren B, Suarez A, Evans RM. Effects of an asthma management program on the asthmatic member: Patient-centered re- sults of a 2-year study in a managed care organization. Am J Manag Care 1998;4:1288.

19. Vincor F. Diabetes mellitus and asthma: "Twin" challenges for public health and managed care systems. Am J Prev Med 1998;14:87.

20. Bukstein D. Asthma in the workplace: Implications for the employer. Am J Integrated Healthcare 1997; $1: 43$.

Address reprint requests to: Wayne N. Burton, M.D. Senior Vice President Corporate Medical Director Bank One 1 Bank One Plaza Chicago, IL 60670-0006

E-mail: wayne_n_burtonmd@bankone.com 
This article has been cited by:

1. Alan Johnson, Gregory Berg, Edward Fleegler, Marilyn Sauerbrun . 2005. A Matched-Cohort Study of Selected Clinical and Utilization Outcomes for an Asthma Care Support ProgramA Matched-Cohort Study of Selected Clinical and Utilization Outcomes for an Asthma Care Support Program. Disease Management 8:3, 144-154. [Abstract] [PDF] [PDF Plus]

2. Shirley A Musich, Alyssa B Schultz, Wayne N Burton, Dee W Edington. 2004. Overview of Disease Management Approaches. Disease Management \& Health Outcomes 12:5, 299-326. [CrossRef] 